\title{
Fibrinolytic Balance of the Arterial Wall: Pulmonary Artery Displays Increased Fibrinolytic Potential Compared with Aorta
}

\author{
Raphael Rosenhek, Irina Korschineck, Elisabeth Gharehbaghi-Schnell, \\ Johannes Jakowitsch, Diana Bonderman, Kurt Huber, Martin Czerny, \\ Raymond R. Schleef, Gerald Maurer, and Irene M. Lang
}

Departments of Cardiology (RR, IK, EG-S, JJ, DB, KH, GM, IML) and Cardiothoracic Surgery (MC), University of Vienna, and the Ludwig Boltzmann Institute for Cardiovascular Research, Vienna, Austria; and the Scripps Research Institute (RRS), La Jolla, California

\begin{abstract}
SUMMARY: Classic pulmonary thromboembolism research has documented that large pulmonary thromboemboli lyse spontaneously, suggesting potent fibrinolytic activity in human pulmonary artery $(\mathrm{Pa})$. This concept conflicts with published animal studies in which the proximal Pa was reported to be devoid of tissue plasminogen activator (t-PA) expression. The current study used in situ hybridization protocols to demonstrate t-PA expression in samples of human main Pa $(n=30)$. Real-time PCR was used to demonstrate quantitatively that the levels of t-PA transcripts were higher than those of its primary regulator [ie, plasminogen activator-inhibitor 1 (PAI-1)] in the Pa samples. Immunologic and functional assays extended these observations by demonstrating that levels of t-PA antigen were higher than PAl-1 antigen, which resulted in the detection of free t-PA activity. This contrasted with the fibrinolytic balance of matched samples of aorta $(n=6)$ in which PAl- 1 transcripts and antigen values were higher than the corresponding t-PA values, and only $\mathrm{M}_{\mathrm{r}} 110 \mathrm{kDa}$ t-PA-PAl-1 complexes could be detected in functional assays. To assess the relative fibrinolytic contribution of the endothelial cell layer, $\mathrm{Pa}$ endothelial cells and aortic endothelial cells were scraped and propagated in culture for $20 \pm 6$ days. Pa endothelial cell-conditioned media revealed increased t-PA/PAI-1 antigen ratios. Taken together, our data indicate that the balance between t-PA and PAl-1 is shifted in human main Pa to favor net PA activity. (Lab Invest 2003, 83:871-876).
\end{abstract}

$P$ ulmonary thromboemboli resolve in the majority of cases, leading to restoration of normal pulmonary hemodynamics (Dalen et al, 1969; Fred et al, 1966; Murphy and Bulloch, 1968; Paraskos et al, 1973; Tow and Wagner, 1967). Resolution may occur by mechanical fragmentation (Wagenvoort, 1995), through organization of the thromboembolus by invasion of capillary buds and fibroblasts leading to recanalization, or through endogenous thrombolysis. Venous thromboemboli fail to lyse in a only small percentage of cases, thereby resulting in chronic thromboembolic pulmonary hypertension (Moser et al, 1990). These data derived from early stages of pulmonary embolism research lead to the conclusion that the pulmonary circulation harbors remarkable capacity with respect to induction of thrombolysis (Dalen et al, 1966; Todd, 1972). Because proteases of the

\section{DOI: 10.1097/01.LAB.0000073127.46392.9D}

Received February 28, 2003.

This research was supported in part by Austrian fellowship Grants FWF P10559-MED and P13834-MED, Anton Dreher Stiftung, and "Vermächtnis Josefine Hirtl zur Förderung der Medizinischen Forschung” (to IML).

Address reprint requests to: Dr. I. Lang, Department of Internal Medicine II, Division of Cardiology, University of Vienna, Vienna, Austria. E-mail: irene.lang@univie.ac.at fibrinolytic system are crucial to the degradation of pulmonary thrombi (Carmeliet et al, 1994), we speculated that, in humans, altered expression of tissue plasminogen activator (t-PA) accounts for this observation. However, data derived from animal studies document that t-PA is not expressed in the main pulmonary artery (Pa) (Levin and del Zoppo, 1994). To define the mechanism by which the pulmonary vascular bed is especially efficient for removal of thromboemboli, fibrinolytic gene expression was investigated in the proximal human $\mathrm{Pa}$ and contrasted with that in a systemic human artery of comparable size, the aorta (Ao).

\section{Results and Discussion}

In contrast to animal models in which pulmonary vascular t-PA expression was shown to be confined to the endothelium of distinct vessels measuring 7.5 to $30 \mu \mathrm{m}$ in diameter (Levin and del Zoppo, 1994; Levin et al, 1997), our analysis revealed t-PA expression in endothelial cells (EC) and smooth muscle cells (SMC) of human main $\mathrm{Pa}$ (Fig. 1). In contrast to t-PA, urokinase-type PA is expressed only at low levels in proximal $\mathrm{Pa}$ and $\mathrm{Ao}$ of normal individuals, whereas it may be up-regulated under pathologic conditions (Lang et al, 1998). More specifically, in situ hybridiza- 


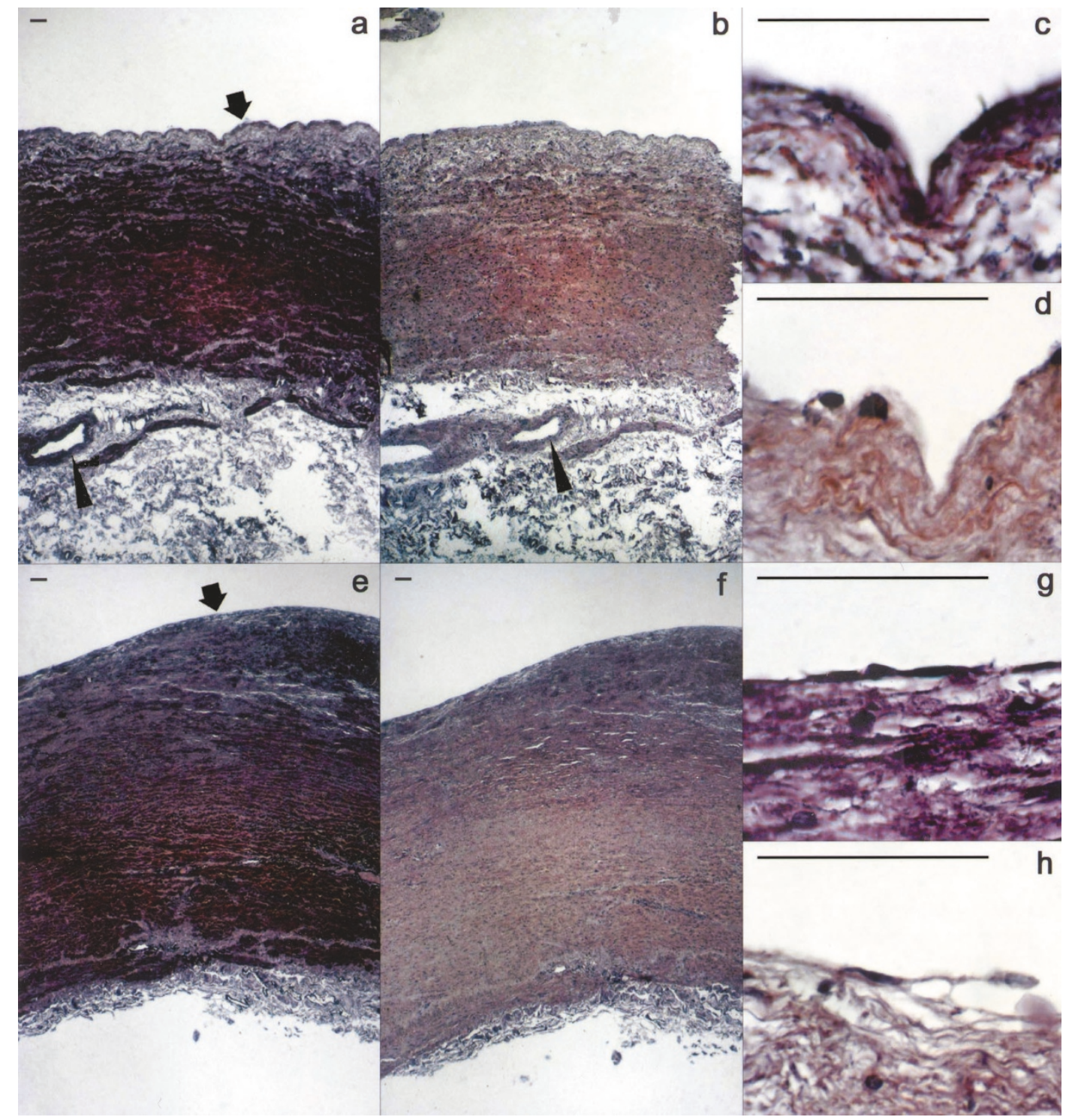

Figure 1.

Localization of tissue plasminogen activator (t-PA) mRNA by in situ hybridization analysis of pulmonary artery $(\mathrm{Pa})$ and aorta $(\mathrm{Ao})$ from the same individual. Purple immunoreactivity indicates positive hybridization signal. Sections have been counterstained with hematoxylin. A, t-PA expression in the Pa medial layer and within the adventitia in the muscular layer of the vasa vasorum, and for comparison, in the corresponding ascending Ao (e to $\mathrm{h}$, arrowheads point to vasa vasorum; all $\times 40$ magnification). b and f, Parallel sections hybridized with the sense control riboprobe. c, t-PA in situ hybridization signal localized within Pa endothelial cells (PaECs; arrow in a); g, a corresponding experiment demonstrating signal within aortic endothelial cells (AoECs; arrow in e). Control experiments using sense probes are shown in $\mathrm{d}$ and $\mathrm{h}(\times 1000$ magnification, oil immersion). Scale bars, $10 \mu \mathrm{m}$.

tion with an antisense riboprobe for t-PA demonstrated expression in medial SMCs and ECs of Pa (Fig. 1, a and c) and Ao (Fig. 1, e and g). This pattern corresponds to t-PA expression detected by immunohistochemistry, with predominant staining of ECs and some weaker immunoreactivity of medial layer SMCs (data not shown). All these observations contrast with the view that during rat development, t-PA is present in the large arteries of both the thoracic and cranial cavities, including the dorsal $\mathrm{Ao}$ and $\mathrm{Pa}$, but gradually disappears from larger vessels (Levin et al, 2000). Our data show that the $\mathrm{Pa}$ plasminogen activation system of humans is clearly different from that of nonhuman primates (Levin and del Zoppo, 1994), mice (Levin et al, 1998), and rats (Levin et al, 2000).
Results from several independent real-time PCR experiments (eight $\mathrm{Pa}$ and $\mathrm{Ao}$ whole wall vessel pairs) demonstrated that t-PA expression did not differ between the two vessels (Fig. $2 \mathrm{a}, p=0.26$ ). However, plasminogen activator inhibitor-1 (PAl-1) expression was significantly lower in $\mathrm{Pa}$ compared with Ao (Fig. $2 b, p=0.046)$. To substantiate these data, fibrin autography was performed. Homogenates from $\mathrm{Pa}$ displayed a large zone of fibrinolytic activity, indicating free t-PA under these conditions. In contrast, a corresponding Ao sample demonstrated a zone of fibrinolysis known to be t-PA (Lang et al, 1993), as well as a t-PA-PAl-1 complex (representative examples shown in Fig. 3a). Western blot experiments under reducing conditions confirmed that specimen t-PA migrates at a 
a

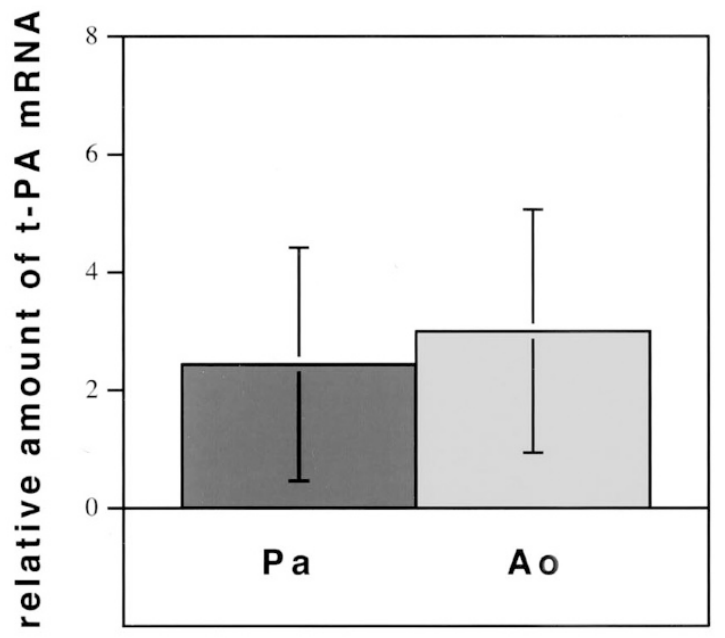

b

$p=0.046$

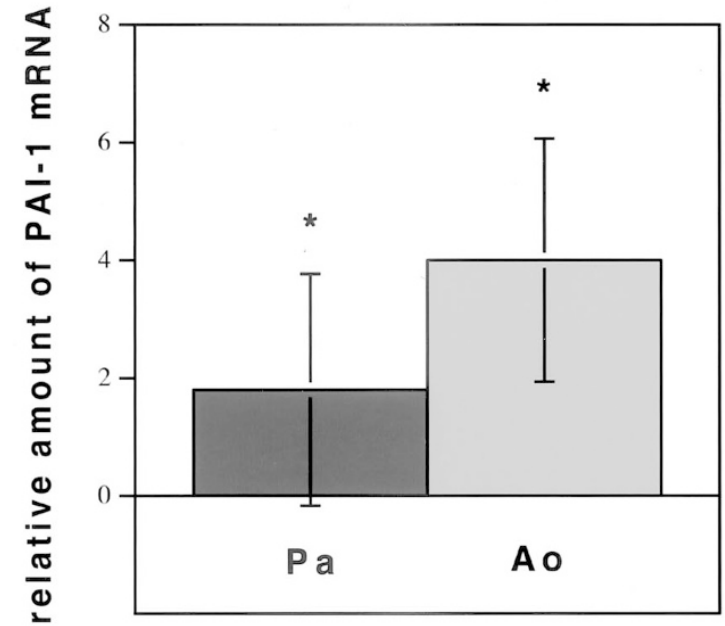

Figure 2.

Real-time PCR analysis of t-PA (a) and plasminogen activator inhibitor 1 (PAl-1) (b) gene expression in Pa and Ao isolated from the same individual, in comparison with glyceraldehyde-3-phosphate dehydrogenase gene expression. Defined dilutions of cDNA were amplified to determine the linear relationship between the threshold cycle (Ct) and the log starting copy number. In all experiments the correlation coefficients were between 0.98 and 0.99 . Quantitation relies on the detection of Ct, which represents the cycle when a fluorescence signal exceeds the mean of background fluorescence plus 10 times the standard deviation in cycles 3 to 15 . Plotting the log of the starting copy number of template molecules for several standard concentrations versus Ct reveals a linear correlation. The bars show the ratios between t-PA and PAl-1 Cts and glyceraldehyde-3-phosphate dehydrogenase Ct. Arbitrary units of the relative amount of the gene of interest are displayed on the $y$-axis. The differences illustrated in b were statistically significant. Error bars represent standard deviations.

lower position than t-PA standard (Fig. 3b). As expected, Ao and $\mathrm{Pa}$ do not display significant quantities of urokinase (Fig. 3c). Furthermore, differential protein analysis of six vessel pairs revealed an increase of more than 3 -fold $(p=0.02)$ in the t-PA/PAl- 1 ratio of Pa compared with Ao (Fig. 4a). In view of these data, it was not surprising that there was lower PAl-1 activity in extracts from Pa compared with Ao (Fig. 4b, $p=0.04)$. Within hours after pulmonary thromboembolism, a sequential up-regulation of t-PA and PAl-1 occurs in the wall of mainstem Pa (Lang et al, 1998). The elevated t-PA/PAl-1 ratio reflects decreased steady-state expression of PAl-1 in $\mathrm{Pa}$, at the mRNA and protein level, with free t-PA rapidly accessible for thrombolysis in the $\mathrm{Pa}$ vessel wall and minimal or no formation of high $\mathrm{M}_{\mathrm{r}} \mathrm{t}-\mathrm{PA}-\mathrm{PAl}-1$ complexes.

Because of the immediate impact of a thromboembolus on the EC surface (Lang et al, 1998), the contribution of the EC layer to the fibrinolytic balance is important. Therefore, t-PA and PAI- 1 antigens were analyzed in conditioned medium from parallel cultures of the same donor. ECs adhered within the first 8 hours after plating, forming numerous small colonies, and reached confluence after $19 \pm 5$ days [Pa endothelial cells (PaECs), $n=6$ ] and $20 \pm 5$ days [aortic endothelial cells (AoECs), $n=6$ ]. A significant difference in t-PA antigen levels was observed between media conditioned by PaECs $\left(7.5 \pm 2.5 \mathrm{ng} / 10^{5} \mathrm{cells}\right)$ and media conditioned by AoECs (3.9 $\pm 2.2 \mathrm{ng} /$ $10^{5}$ cells, $\left.p=0.02\right)$. In contrast, there was no difference in PAl- 1 antigen ( $p=0.37)$ or PAl- 1 activity levels $(p=0.32$, Fig. 5). The increased secretion of t-PA protein may facilitate rapid fibrinolysis in response to acute pulmonary thromboembolism. In vitro, the fi- brinolytic system of ECs adopts unphysiologic expression patterns, eg, up-regulation of t-PA and downregulation of $\mathrm{PAl}-1$, paralleling the length of time in culture (Lang et al, 1994b). However, a comparison between two vascular compartments using primary cells with an identical genetic background during a short period of time in culture allows the assessment of differences in in vivo fibrinolytic gene expression (Lang et al, 1994b).

The data demonstrate that the main $\mathrm{Pa}$ wall harbors a unique profile of fibrinolytic gene expression. Enhanced fibrinolytic activity as a result of higher t-PA antigen concentration compared with PAI-1 antigen concentration and the presence of free t-PA suggests a basis for spontaneous lysis of emboli in the pulmonary trunk.

\section{Materials and Methods}

\section{Subjects and Collection of Specimens}

Circumferential cuts of Pa trunk and ascending Ao, 1 to $2 \mathrm{~cm}$ above the respective semilunar valves, were harvested from donors for heart and lung transplantation. Before further experimental workup, the luminal sides of the vessels were inspected for signs of atherosclerosis, and if present, sample pairs were not included into the analysis. ECs were harvested by a gentle scrape with a no. 10 blade (Lang et al, 1994b). Patient age was $51.1 \pm 17.7$ years (mean $\pm \mathrm{SD}$ ). Mean pulmonary vascular resistance was $216 \pm 90.4$ dynes.sec.cm 5 . Confounding factors within the patients' clinical backgrounds were accounted for by comparing paired values of a single individual. $A$ 
a

b

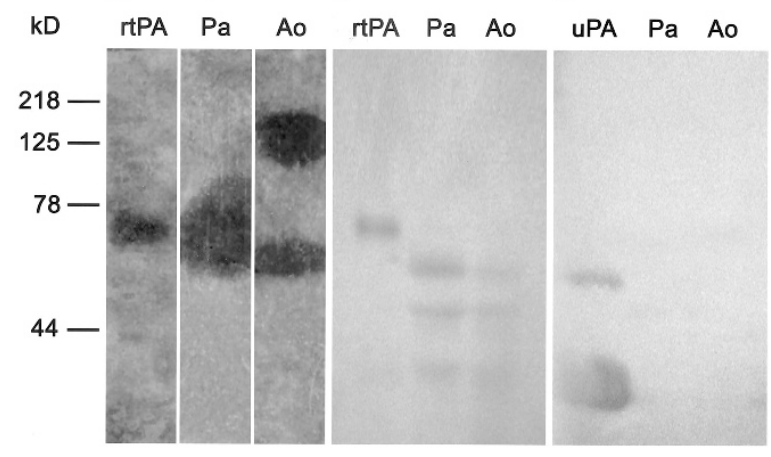

Figure 3.

a, SDS-PAGE and fibrin autography of whole vessel extracts of a representative pair of $\mathrm{Pa}$ and Ao. The Biorad Kaleidoscope Prestained Standards 61-0234 were used for sizing of proteins. Recombinant t-PA (50 ng) was loaded in lane $r t-P A$. Ao protein extracts $(5 \mu \mathrm{g})$ (lane $A o)$ and Pa protein extracts $(5 \mu \mathrm{g})$ (lane $\mathrm{Pa}$ ) were loaded. Photographs were taken after prolonged exposure at $37^{\circ} \mathrm{C}$ to favor visualization of t-PA-PAl-1 complexes. $b$, Western blot experiment using anti-t-PA to visualize $50 \mathrm{ng}$ of recombinant human t-PA, $30 \mu \mathrm{g}$ of Ao protein extract (lane $\mathrm{Ao}$ ), and $30 \mu \mathrm{g}$ of $\mathrm{Pa}$ protein extract (lane $\mathrm{Pa}$ ). The additional lower bands are thought to represent cleaved t-PA. Under the given conditions, t-PA-PAl-1 complexes are not visualized. Negative controls in the absence of primary antibody did not show any bands. C, Western blot experiment using anti-urokinase-type PA to visualize 30,000 IU of human urokinase-type PA, 30 $\mu \mathrm{g}$ of Ao protein extract (lane $\mathrm{Ao}$ ), and $30 \mu \mathrm{g}$ of $\mathrm{Pa}$ protein extract (lane $\mathrm{Pa}$ ).

total of 74 vessels were studied, including 6 matched pairs of $\mathrm{Pa}$ and Ao for protein analysis, 8 matched pairs of $\mathrm{Pa}$ and Ao for real-time PCR analysis, and 8 pairs of $\mathrm{Pa}$ and Ao from the same donor for parallel in situ hybridization experiments. In addition, 30 unmatched $\mathrm{Pa}$ specimens were used for in situ hybridization studies. Samples were obtained according to a protocol approved by the Institutional Review Board of the University of Vienna, Austria (EKZ 96/294). Both Pa and Ao

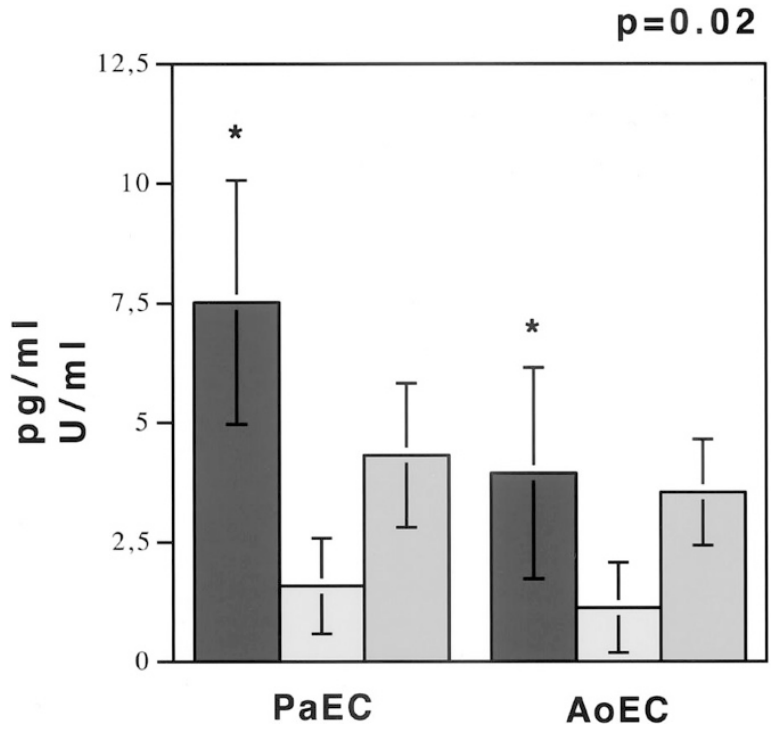

Figure 5.

Levels of t-PA, PAl- 1 antigen, and PAl-1 activity in medium conditioned by unpassaged PaECs and AoECs from the same individual $(n=6)$. ECs were grown to confluence in $20 \%$ fetal bovine serum, and 24 -hour serumcontaining conditioned media was prepared. t-PA and PAI-1 levels were measured by ELISA as described in "Materials and Methods" in conditioned media of primary ECs cultured under basal conditions. Black bars represent t-PA antigen levels, light gray bars represent PAl-1 antigen levels/100, and gray bars represent PAl-1 activity values.

were analyzed from each patient using paired $t$ tests. Ap value $<0.05$ was considered significant.

\section{Protein Extraction, ELISA Assays, SDS-PAGE, Western Blots, Fibrin Autography, and Tissue Culture}

Protein extraction was performed using a standard procedure. Tissues were harvested fresh and $1 \mathrm{gm}$ of

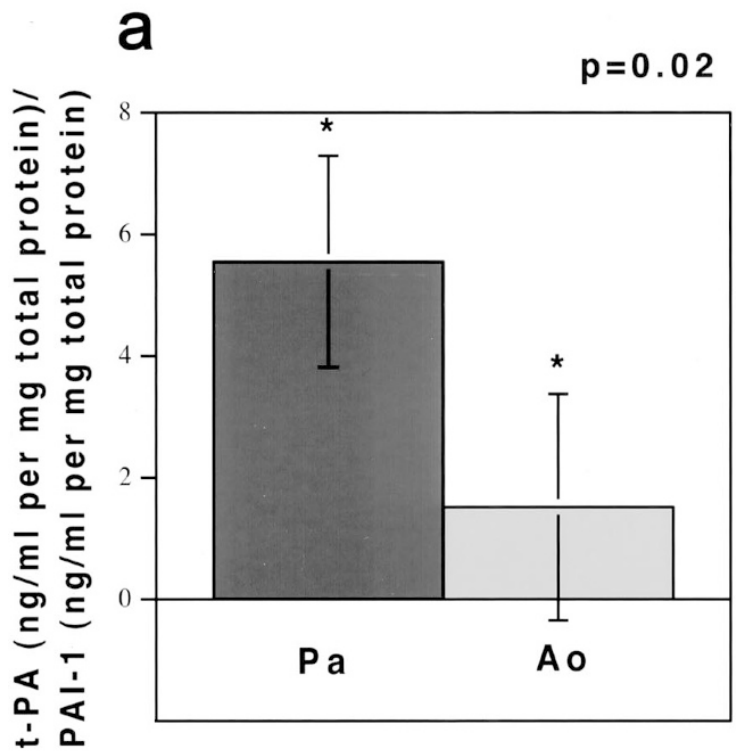

b

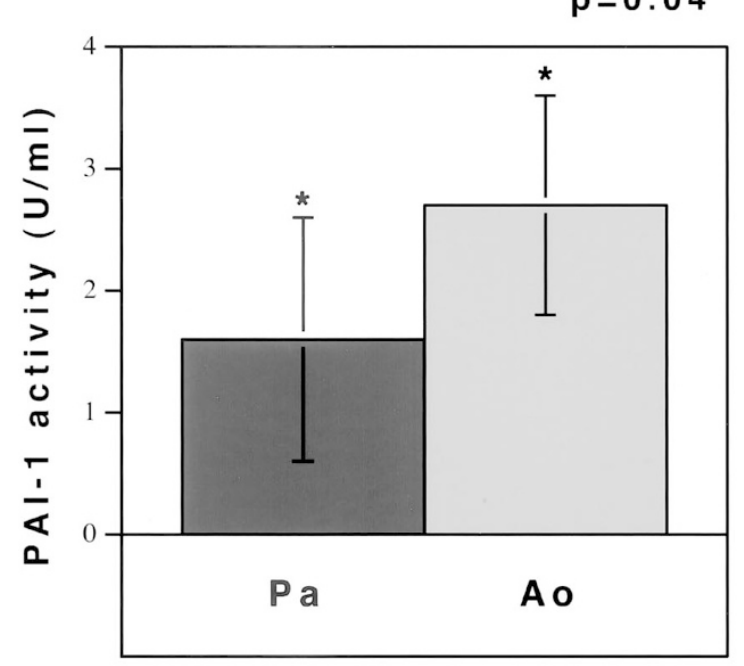

Figure 4.

a, T-PA and PAl-1 antigen analyses of extracts of whole Pa and Ao wall isolated from the same individual ( $n=6$ pairs). The bars represent t-PA-PAI-1 ratios. b, PAl-1 activity analysis of extracts of $\mathrm{Pa}$ and Ao isolated from the same individual ( $n=6$ pairs). 
whole vessel wall was homogenized in PBS $(\mathrm{pH}=7.4)$ containing $0.1 \%$ Triton $\mathrm{X}-100$ using a rotating blade (TissueMizer, IKA Labortechnik, Germany). Homogenates were incubated at $4^{\circ} \mathrm{C}$ for 8 hours with gentle agitation. The extracts were centrifuged at $10,000 \times g$ ( $4^{\circ} \mathrm{C}, 20$ minutes) and the supernatants subjected to a protein assay (BCA assay; Pierce, Rockford, Illinois). Equal amounts of protein were assayed by ELISA and fibrin autography. Samples were analyzed pairwise per patient and not pooled. For the measurement of t-PA, a two-site immunoassay was used as previously described (Lang et al, 1994b). PAl-1 activity was measured using immobilized t-PA to bind active PAI-1 as described (Christ et al, 1993). SDS-PAGE, Western blots, and fibrin autography were performed according to published protocols (Lang et al, 1993; Lang and Schleef, 1996). Goat anti-human melanoma t-PA IgG (product no. 387) and human affinity-purified urokinase $m A b$ against $B$ chain (product no. 3689) were from American Diagnostica (Greenwich, Connecticut). ECs were grown to confluence and cultured as described in detail (Lang et al, 1994b). Medial SMC were not systematically analyzed in culture because of the difficulty in obtaining a representative cell population (Stenmark and Frid, 1998).

\section{Molecular Techniques}

Total RNA was extracted from specimens stored in liquid nitrogen immediately after harvest in the operating room (Chomczynski and Sacchi, 1987). For reverse transcription, the 1st Strand cDNA Synthesis Kit for RT-PCR (AMV; Boehringer Mannheim, Mannheim, Germany) was used.

To investigate the relative expression of t-PA mRNA in $\mathrm{Pa}$, we used an RT-PCR protocol with $\mathrm{Pa}$ and $\mathrm{Ao}$ whole vessel sample pairs $(n=8)$. Because quantitation of differential expression is only valid in the logarithmic phase of amplification, a real-time PCR assay was optimized. This RNA quantitation assay is based on the 5'-3' endonuclease activity of TaqDNA polymerase to cleave a TaqMan probe during PCR. PCR reactions are performed in the presence of three sequence-specific oligonucleotides. Two of them serve as conventional PCR primers for the amplification of target molecules. The third oligonucleotide, the TaqMan probe, contains a reporter dye at its $5^{\prime}$ end and a quencher dye at its $3^{\prime}$ end and hybridizes to the generated template. During the reaction, cleavage of the probe separates the reporter dye and the quencher dye, which results in increased fluorescence of the reporter dye. The fluorescence emitted is directly proportional to the number of template molecules in the tube. The accuracy of this method is based on the determination of the threshold cycle (Ct) within the logarithmic phase of the amplification as opposed to the end point determination of conventional PCR. All PCR assays were performed (Heid et al, 1996) in duplicates and run on an ABI PRISM 5700 Sequence Detector System (Perkin Elmer, Foster City, California). Effective primer and probe combinations were as follows: PAI-1-740F (position 740-757), tgc- ccatgatggctcaga; PAl-1-824R (803-824), ggcagttccaggatgtcgtagt; PAI-1 probe (775-797), actgagttcaccacgcccgatgg; t-PAF (933-955), tgacgtgggagtactgtgatgtg; t-PAR (1019-1036), ggcgatgtcggcgaaga; t-PA probe (961-982), ctgctccacctgcggcctgaga (all sequences $5^{\prime}$ to $\left.3^{\prime}\right)$.

In situ hybridization was performed as described (Lang et al, 1994a). An EcoRl-Hindlll fragment of pGEM3Z human t-PA (a gift from Dr. Tor Ny, Uppsala, Sweden) containing nucleotides 1370-1985 was used (Edlund et al, 1983).

\section{Acknowledgements}

RR, IK, EGS, JJ, DB, and IML performed the laboratory work. $\mathrm{KH}, \mathrm{RRS}$, and $\mathrm{GM}$ provided intellectual support. MC collected tissues. Part of the data represent the thesis work of RR.

\section{References}

Carmeliet P, Schoonjans L, Kieckens L, Ream B, Degen J, Bronson R, De Vos R, van den Oord JJ, Collen D, and Mulligan RC (1994). Physiological consequences of loss of plasminogen activator gene function in mice. Nature 368: 419-424.

Chomczynski P and Sacchi N (1987). Single-step method of RNA isolation by acid guanidinium thiocyanate-phenolchloroform extraction. Anal Biochem 162:156-159.

Christ G, Seiffert D, Hufnagl P, Gessl A, Wojta J, and Binder BR (1993). Type 1 plasminogen activator inhibitor synthesis of endothelial cells is downregulated by smooth muscle cells. Blood 81:1277-1283.

Dalen JE, Banas JSJ, Brooks HL, Evens GL, Paraskos JA, and Dexter L (1969). Resolution rate of acute pulmonary embolism in man. N Engl J Med 280:1194-1199.

Dalen JE, Mathur VS, Evans H, Haynes FW, Pur-Shahriari AA, Stein PD, and Dexter L (1966). Pulmonary angiography in experimental pulmonary embolism. Am Heart J 72:509-520.

Edlund T, Ny T, Ranby M, Heden LO, Palm G, Holmgren E, and Josephson S (1983). Isolation of cDNA sequences coding for a part of human tissue plasminogen activator. Proc Natl Acad Sci USA 80:349-352.

Fred HL, Axelrad MA, Lewis JM, and Alexander JK (1966). Rapid resolution of pulmonary thromboemboli in man: An angiographic study. JAMA 196:1137-1139.

Heid CA, Stevens J, Livak KJ, and Williams PM (1996). Real time quantitative PCR. Genome Res 6:986-994.

Lang IM, Marsh JJ, Konopka RG, Olman MA, Binder BR, Moser KM, and Schleef RR (1993). Factors contributing to increased vascular fibrinolytic activity in mongrel dogs. Circulation 87:1990-2000.

Lang IM, Marsh JJ, Olman MA, Moser KM, Loskutoff DJ, and Schleef RR (1994a). Expression of type 1 plasminogen activator inhibitor in chronic pulmonary thromboemboli. Circulation 89:2715-2721.

Lang IM, Marsh JJ, Olman MA, Moser KM, and Schleef RR (1994b). Parallel analysis of tissue-type plasminogen activator and type 1 plasminogen activator inhibitor in plasma and endothelial cells derived from patients with chronic pulmonary thromboemboli. Circulation 90:706-712. 
Lang IM, Moser KM, and Schleef RR (1998). Elevated expression of urokinase-like plasminogen activator and plasminogen activator inhibitor type 1 during the vascular remodeling associated with pulmonary thromboembolism. Arterioscler Thromb Vasc Biol 18:808-815.

Lang IM and Schleef RR (1996). Calcium-dependent stabilization of type I plasminogen activator inhibitor within platelet alpha-granules. J Biol Chem 271:2754-2761.

Levin EG, Banka CL, and Parry GC (2000). Progressive and transient expression of tissue plasminogen activator during fetal development. Arterioscler Thromb Vasc Biol 20:16681674.

Levin EG and del Zoppo GJ (1994). Localization of tissue plasminogen activator in the endothelium of a limited number of vessels. Am J Pathol 144:855-861.

Levin EG, Osborn KG, and Schleuning W-D. (1998) Vesselspecific gene expression in the lung. Chest 114:68S.

Levin EG, Santell L, and Osborn KG (1997). The expression of endothelial tissue plasminogen activator in vivo: A function defined by vessel size and anatomic location. J Cell Sci 110:139-148.
Moser KM, Auger WR, and Fedullo PF (1990). Chronic major-vessel thromboembolic pulmonary hypertension. Circulation 81:1735-1743.

Murphy ML and Bulloch RT (1968). Factors influencing the restoration of blood flow following pulmonary embolization as determined by angiography and scanning. Circulation 38:1116-1126.

Paraskos JA, Adelstein SJ, Smith RE, Rickman FD, Grossman W, Dexter L, and Dalen JE (1973). Late prognosis of acute pulmonary embolism. N Engl J Med 289:55-58.

Stenmark KR and Frid MG. (1998) Smooth muscle cell heterogeneity: Role of specific smooth muscle cell subpopulations in pulmonary vascular disease. Chest 114:82S-90S.

Todd AS (1972). Endothelium and fibrinolysis. Atherosclerosis $15: 137-140$.

Tow DE and Wagner HNJ (1967). Recovery of pulmonary arterial flow in patients with pulmonary embolism. N Engl J Med 276:1053-1059.

Wagenvoort CA (1995). Pathology of pulmonary thromboembolism. Chest 107:10S-17S. 